\title{
Effect of Jigsaw Technique and Gender on Students' Attitude to Ethnic Integration and Sustainable Development in Nigeria
}

\author{
Ajitoni Sunday Olukayode ${ }^{1} \&$ Salako, Ekima Tina ${ }^{1, *}$ \\ ${ }^{1}$ Department of Teacher Education, Faculty of Education, University of Ibadan, Nigeria \\ *Corresponding author: Department of Teacher Education, Faculty of Education, University of Ibadan, Nigeria. Tel: \\ 234-803-312-2132. E-mail: sajitoni2006@yahoo.com
}

Received: March 11, 2014

Accepted: April 10, 2014

Online Published: May 23, 2014

doi:10.5430/wje.v4n3p46

URL: http://dx.doi.org/10.5430/wje.v4n3p46

\begin{abstract}
The growing spate of ethno-religious crises and insurgency that characterizes Nigerian polity has been traced to inadequacies in the integration policies of the government. These situations have resulted in loss of several lives and unquantifiable psychological and material damages. However, the situations could improve through the use of effective teaching strategy which could restructure the prejudiced minds of students and encourage respect for other cultures. Therefore, the Jigsaw technique has been identified as a useful cooperative learning strategy that could be used for promoting national unity through education. The use of Jigsaw technique could discourage discrimination and promote mutual respect for other cultures. This study, therefore, examined jigsaw technique as an effective approach for ethnic integration and sustainable development in Ogun state, Nigeria. Two null hypotheses were generated and tested at 0.05 level of significance. The study adopted a pretest- posttest, control group, quasi experimental design. A 30 item achievement test was administered on 126 junior secondary school students selected from two secondary schools in the south-west region of Nigeria. Data were analysed using analysis of co-variance. The findings of this study revealed that jigsaw technique benefited students who form jigsaw group (experimental group) than the conventional learning group (control group). Based on these findings, it is suggested that jigsaw technique should be used to complement the conventional lecture method as this could promote unity and peaceful co-existence among students. This could further translate into better integration and sustainable development in Nigeria.
\end{abstract}

Keywords: diversity; ethnic integration; social studies; sustainable development; multicultural education

\section{Introduction}

Nigeria's attempts to forge national integration and sustainable development amongst her ethnically diverse peoples have not been an easy task. The highly diversified ethnic and linguistic dimensions of the Nigerian polity have impacted greatly on national integration and sustainable development, such that insecurity and other divisive forces have negated the realization of the ideals of democratic governance in the country. Effective management of such diversity in the society is a challenge, hence, the increased recognition on the part of governments worldwide for better public policies of managing cultural diversity (Banks, 2008; 2006; Gay, 2004). Therefore, in an attempt to manage the problems of ethno-religious crises and insurgencies in Nigeria, various policy frameworks towards attaining national unity have been put in place by the government (Maduabum, 2006).

In the interest of national unity and in the spirit of post war reconstruction, rehabilitation, reconciliation and to foster the spirit of oneness the Gowon regime in 1973, introduced the National Youth Service Corps Scheme (Uwechue, 2004). Further, to foster unity among Nigerian youths through education, drawing from the example of Argentina, in 1966, the Federal Government established what was then known as Inter Regional Secondary Schools and later called Federal Government Colleges. These are now known as unity schools which were established with an aim to achieve unity in the post-civil war era in keeping with the federal character. However, several of these policies put in place to check ethnicity failed to yield results. Rather, it resulted into growing spate of crises in the society. According to Alapiki (2005), it is clear that the outcomes of integration policies and programmes in Nigeria have fallen far below expectation, ethnic particularism is seen as the major cause of this failure.

Consequently, one way of producing well informed citizens who could contribute to national development is by 
equipping people with adequate knowledge of how to work and live together harmoniously in any society (Ghosh and Abidi, 2004). Education, therefore, remains the core of national stability in a world where people continually encounter problems such as racism, sexism, prejudice and discrimination in the society. In agreement with these views, Moronkola (2012) states that education is regarded as a tool that can accommodate the ethnic, cultural and religious diversities of a country and enhance societal development and transformation. In the same vein, Nevin (2008) explains that good quality education is an essential tool for achieving a more sustainable world. Further, Nevin (2008) opines that this was emphasised at the UN World Summit in Johannesburg in 2002 where the reorientation of current education systems was outlined as key to sustainable development.

Sustainable development ensures the well-being of the people by integrating social development, economic development, environmental conservation, security and protection into the fabrics of the society. These changes must be seen in the eradication and alleviation of the widespread conditions of poverty, unemployment and inequitable social conditions. Improvement of quality of life means the putting in place of change which ensures that every person lives a life of dignity or life in a society that respects and helps him/her realize nearly all human rights. In pursuance of the attainment of these lofty objectives, Social Studies curriculum, therefore, considers it significant to employ appropriate instructional strategies which could provide subtle but potent forum for achieving these objectives (Ojebiyi and Salako, 2013). Hence, this paper determined the effect of jigsaw technique and gender on students' attitude to ethnic integration and sustainable development in Social Studies classrooms in Nigeria.

\section{Jigsaw Technique}

Jigsaw is based on organizing students in groups that are mixed as heterogeneously as possible. First, academic abilities, and then on the basis of ethnic backgrounds, race, and gender. Lucas (2000: 221) explains that Jigsaw technique allows students to actively participate in learning process. By being constantly subjected to this method, they should feel more comfortable about their roles. Ways of evaluating the groups can enhance the effectiveness of the jigsaw technique by making each student have a sense of responsibility for their group's performances. According to Francis (2013), the technique enables students from different ethnic and religious backgrounds and gender to work together, interact and achieve in ways and at levels that are rarely found in other instructional strategies. It also leads to students being tolerant of diverse viewpoints, to consider others' thoughts and feelings in depth, and seek more support and clarification of others' positions, irrespective of the ethnic or religious background and gender of the other person. According to Enuoka (2005), these are elusive issues amongst the various ethnic and religious groups in Nigeria

Doymus, Simsek and Bayrakceken (2004) are of the opinion that Jigsaw technique supports cooperative learning by giving each student the responsibility to teach a part of the subject. The technique encourages equal opportunity for success. Every student must believe that he or she has an equal chance of learning the content and abilities, and earns the group rewards for academic success, regardless of the group he or she belongs to. The ethnic groups in Nigeria have been so stratified that the major ethnic groups are favoured in the scheme of things at the expense of minority groups. Moreover, Kegan (2001) states that there is a display of positive interdependence and positive social interaction behaviours and attitudes in jigsaw learning sessions. These are conditions that are necessary for national integration and sustainable development but which have for long eluded Nigerian citizens. A start in the classroom with young learners who are not yet fully prejudicial and ethnocentric might be worthwhile.

As a result of its multiple instances in promoting interaction, the jigsaw technique has become one of the most widely used learning techniques at all academic levels. Students who do not like to participate in a conventional classroom setting generally feel more comfortable speaking up in the small groups found in Jigsaw classrooms. The learning effectiveness of the conventional classroom has been questioned because of the lack of adequate interaction between the instructor and students. Classrooms will continue to reflect the increasing diversity of the population as the number of students from racially, ethnically and culturally diverse backgrounds grow. This reality will require flexibility and modifications in the instructional and classroom practices of teachers as they respond to the needs of their diverse learners' interaction and develop in them attitudes.

\section{Jigsaw Technique and the Conventional Lecture Strategy}

The conventional lecture strategy is still the most frequently used method of instruction in schools today. The techniques involved in the method serve as the basis for other methods of training. Ojebiyi and Salako (2013) explain that the conventional strategy is a teaching method whereby an instructor is the central focus of information transfer. 
The learning effectiveness of the conventional classroom has been questioned because of the lack of adequate interaction between the instructor and students. According to Ogunleye (2002) it yields less deep knowledge when compared with other strategies. Therefore, teachers must respond to the needs of every learner and develop positive attitudes. Francis (2013) is of the view that when compared with traditional teaching methods, the jigsaw has several benefits or advantages or importance. First and foremost, most teachers find jigsaw easy to learn because teacher is not the sole provider of knowledge which makes most teachers enjoys working with it because it can be used with other teaching strategies

However, Francis (2013) adds that there can be some obstacles when using the jigsaw technique. One common problem is student dominance. In order to reduce this problem, each jigsaw group has an appointed leader. Students realize that the group is more effective if each student is allowed to present his or her own material before questions and comments are made. Dominance is eventually reduced because students realize it is not in the best interest of the group. Another issue according to Francis (2013) is that of bright students becoming bored. Research suggests that there is less boredom of bright students in the jigsaw classroom than in the traditional classroom. Bright students should be encouraged to develop the mindset of a teacher. By being a teacher a boring task can be changed into an exciting challenge. Dealing with students that have been trained to compete can also cause difficulties.

Students who do not like to participate in a conventional classroom setting generally felt more comfortable speaking up in the small groups using jigsaw strategy. This is due to its multiple instances in promoting interaction. Similarly, Doymus (2008) and Moreno (2009) reported that Jigsaw is considerably more effective than individualistic instructional strategy and conventional classroom method. Also, Keramati (2010) indicates that the performance of students taught in jigsaw learning setting was significantly better than those taught using the conventional teaching method. The jigsaw strategy is effective because it promotes mixed groups of students in terms of ethnic, religion, gender and other variables. The elements of jigsaw technique which is a cooperative learning method according to Machaisa, (2004) and Kegan (2001) are positive interdependence, promotive face-to-face interaction, individual accountability, social skills, and group processing. These elements are germane in all aspects of education for the promotion of peaceful co-existence in the society.

\section{Hypotheses}

The following null hypotheses were generated and tested at 0.05 level of significance:

H01: There is no significant main effect of treatment on students' attitude

H02: There is no significant main effect of treatment on students' gender

\section{Method}

The study adopted a pre-test and post-test quasi-experimental design.

\subsection{Sample}

The population sample for this study is junior secondary school students selected from two secondary schools in the south-west region of Nigeria.

\subsection{Instrumentation}

The study employed the following two standardized instruments:

\section{Achievement test on social studies (ATSS)}

The test item consists of thirty items which cut across Social Studies education related issues. The test items were drawn from the universal basic education curriculum on Social Studies education for junior secondary schools designed by Federal ministry of education, science and technology.

\section{Curriculum package on multicultural education (CPME)}

The preparation of the curriculum package on multicultural education was guided by multiculturalism / diversity curriculum guidelines created by National council for social studies (NCSS). It consists of three major topics: Basic knowledge of multicultural education, responsible behaviours and the need for multicultural education. The package contains contents to be taught as well as teachers' and students' activities. It is designed in order to create awareness and promote multicultural values in the students. 


\subsection{Procedure}

Using the random sampling technique, a sample of (126) students were selected for the study.

\subsection{Data Analysis}

Data collected were analysed using descriptive statistics of frequency counts, mean and percentage and standard deviation. ANCOVA statistics was used to test the formulated hypotheses at 0.05 alpha level.

\section{Result}

\section{Research Ho1:}

There is no main significant effect of treatment on students' attitude

Table 1. Summary of Analysis of Covariance on Students’ Attitude

\section{Test of Between-Subjects Effects}

Dependent Variable: Post score

\begin{tabular}{lllllll}
\hline Source & $\begin{array}{l}\text { Type III Sum } \\
\text { of Squares }\end{array}$ & df & $\begin{array}{l}\text { Mean } \\
\text { Square }\end{array}$ & F & Sig. & $\begin{array}{l}\text { Partial Eta } \\
\text { Squared }\end{array}$ \\
\hline Corrected Model & $4367.589^{\text {a }}$ & 8 & 545.949 & 52.571 & .000 & .782 \\
Intercept & 790.877 & 1 & 790.877 & 76.156 & .000 & .394 \\
prescore & 1329.036 & 1 & 1329.036 & 127.976 & .000 & .522 \\
trtmt & 803.645 & 1 & 803.645 & 77.385 & .000 & .398 \\
attitude & 7.037 & 1 & 7.037 & .678 & .412 & .006 \\
gender & 36.595 & 1 & 36.595 & 3.524 & .063 & .029 \\
trtmt*attitude & 2.848 & 1 & 2.848 & .274 & .601 & .002 \\
trtmt*gender & 33.676 & 1 & 33.676 & 3.243 & .074 & .027 \\
attitude*gender & 6.682 & 1 & 6.682 & .643 & .424 & .005 \\
trtmt*attitude*gender & .983 & 1 & .983 & .095 & .759 & .001 \\
Error & 1215.046 & 117 & 10.385 & & & \\
Total & 65428.000 & 126 & & & & \\
Corrected Total & 5582.635 & 125 & & & & \\
\hline
\end{tabular}

a. $\mathrm{R}$ Squared $=.782$ (Adjusted R Squared $=.767$ )

TABLE 1 above shows that there is a significant main effect of treatment on students' attitude $(\mathrm{F}(1,117)=77.39$; $\mathrm{P}<$ 0.05) .Therefore $\mathrm{H} 01$ is rejected. Table shows the magnitude of preference of attitude above the group.

Table 2. Estimated Marginal Means

\section{Estimates}

\section{Dependent Variable: Post score}

\begin{tabular}{lll}
\hline Treatment & Mean & Std. Error \\
\hline experimental group (jigsaw) & $24.964^{\mathrm{a}}$ & .602 \\
control (conventional) & $17.651^{\mathrm{a}}$ & .557 \\
\hline
\end{tabular}

Table 2 further shows that the experimental group which is made of students who were taught using the Jigsaw technique have higher mean score (24.96) than the control group which was exposed to conventional method (17.65).

Ho 2: There is no significant main effect of treatment on students' gender. 
Table 3. Treatment*Attitude*Gender

Dependent Variable: Post score

\begin{tabular}{lllll}
\hline Treatment & Gender & Attitude & Means & Std. Error \\
\hline experimental group (jigsaw) & $\begin{array}{l}\text { male } \\
\text { female }\end{array}$ & $\begin{array}{l}\text { Male } \\
\text { female }\end{array}$ & $24.668^{\mathrm{a}}$ & .601 \\
& & & & $.335^{\mathrm{a}}$ \\
control (conventional) & $\begin{array}{l}\text { male } \\
\text { female }\end{array}$ & $\begin{array}{l}\text { male } \\
\text { female }\end{array}$ & $19.476^{\mathrm{a}}$ & .667 \\
& & $18.804^{\mathrm{a}}$ & .623
\end{tabular}

Based on table 3, there is no significant main effect of treatment on students' gender. There is not much observed difference between the mean score of the female and male students in the experimental group (24.67 and 25.33). Same also in the control group (19.48 and 18.80). Therefore Ho2 is not rejected.

\section{Discussion of the Table}

It was found in this study that there is a significant main effect of treatment on students' attitude. This is to the effect that the experimental group (jigsaw) has higher mean score than the control group which was expose to conventional method which is the traditional method of instruction generally used in most schools. This is as a result of the fact that students who were exposed to the jigsaw strategy were more productive and resourceful. This could be seen in the high level of interaction with each other within the group. Relatedly, Francis (2013) states that there are several benefits of jigsaw technique in teaching. Teacher is not the sole provider of knowledge because most of the work is done by the students themselves which makes it an efficient way to learn. Students take ownership in the work and achievement and therefore students are held accountable among their peers. Jigsaw technique is beneficial in teaching because learning revolves around interaction with peers, students are active participants in the learning process and thereby help to build inter-personal and interactive skills among students.

There is no significant main effect of treatment on students' gender. This is to the effect that there is not much observed difference between the mean score of the female and male students in both the experimental (Jigsaw) and the control group which was expose to conventional method. This is in agreement with the views of Francis (2013) that Jigsaw technique is beneficial in teaching because learning revolves around interaction with peers, students are active participants in the learning process and thereby help to build inter-personal and interactive skills among students. Therefore, the jigsaw technique could be described as gender friendly. Hence, the use of jigsaw learning strategy has the potentials of helping to foster cooperation, mutual trust, and understanding among students irrespective of their differences.

\section{Conclusion}

Jigsaw is a laudable technique for encouraging group sharing, cooperation, mutual, trust and learning of specific content. Abdullah (2010) opines that Jigsaw, one of the cooperative learning techniques, is based on group dynamics and social interactions. Also, Abdullahi (2010) citing Açıkgöz, (2006: 210) says it is one of the "pure” cooperative learning techniques. This is more so in the context of an increasingly diverse academic and cultural backgrounds of students in Nigerian schools. This technique can be used as an instructional activity across several subjects and is best to use when there is a large amount of content to teach. Jigsaw helps students learn cooperation as group members share responsibility for each other's learning by using critical thinking and social skills to complete an assignment. In addition, Jigsaw technique allows students to actively participate in learning process. By being constantly subjected to this method, they should feel more comfortable about their roles.

Thus, the essence of the Social Studies curriculum at all level of education in Nigeria is expected to provide students with insight into the use of a variety of knowledge structures and processes that have relevance in modern civilization. It is concern with fostering better understanding of the movement, events and personalities that have influenced the history of Nigeria. It does not only deal with the controls imposed on our lives by political, social and economics instructions, but also capitalizes on the fostering and improvement of human relations through a better understanding of others both at home and abroad. Salako (2010) states that the ultimate objectives of a Social Studies programme is the development and improvement of living generally, not merely in the classroom but also in the community, country and in the world as whole. Okam (2002) reflects that the curriculum design envisaged in the philosophy behind the 
teaching and learning of Social Studies education has to be seen in term of development of intelligent, responsible and self-directing citizens.

These are people who are expected to contribute productive and meaningful quotas towards democratic government and national integration and sustainability in the twenty-first century Nigeria. The overall principle of Social Studies is to live in unity and harmony as one indivisible, indissoluble, democratic and sovereign nation founded on the principles of freedom, equality and justice (NPE, 2004). Okam (2002) submits that, the Nigerian society requires massive re-organization, redirection, national rebirth, reconstruction and repositioning through the teaching and learning of social studies in all levels of our educational development. He opines that, Nigeria must move form retrogressing to developing and indeed join the club of developed nations of the world. Therefore, through effective Social Studies instructional strategies, such as Jigsaw and other cooperative learning methods, the Challenges posed in achieving sustainable integration in 21st century Nigeria could be overcome.

\section{Recommendations}

It is hereby recommended that:

Teachers should adopt the jigsaw learning technique in the teaching of concepts in Social Studies and indeed across other subject areas in order to better prepare the students for future communal living, understanding of other peoples' culture and development of abilities to live peacefully with others especially outside of their own culture or ethnic origins.

Students should be assisted to appreciate the need for unity, peace, love and harmony and the need to contribute to its entrenchment in the society. This would go a long way to make them more sociable and tolerant of other people's way of life.

Curriculum developers in Social Studies should incorporate more multicultural concepts into the Social Studies curriculum and make them to be in equal proportion in terms of elements of the different cultures, religions and ethnic identification.

Teachers too should learn to be exposed to other teaching strategies apart from the conventional lecture method of teaching in order to bring up active students who could take charge of their affairs.

The Ministry of Education should organize frequent in-service training for teachers in the various schools, particularly on the methods of teaching.

\section{References}

Abdullahi, S. (2010). Effects of jigsaw II technique on academic achievement and attitudes to written expression course. Educational Research and Reviews, 5(12), 77-787.

Alapiki, H. E. (2005). The Political Economy of Globalization. In Alapiki, H. E. (Ed.), The Political Economy of Globalization. Port Harcourt: Amethyst 85 Colleagues Publishers, 208-231.

Banks, J. A. (2006). Cultural diversity and education (5th ed.). Boston: Allyn \& Bacon

Banks, J.A. (2008). An Introduction to Multicultural Education edition. Pearson, Allyn and Bacon.

Doymus K, Simsek U, \& Bayrakceken S. (2004). The effect of cooperative learning on attitude and academic achievement in science lessons. J.Turk. Sci. Educ., 2(2), 103-113.

Doymus, K. (2008). Teaching chemical equilibrium with the Jigsaw technique. Research in Science Education, 38(2), 249-260. http://dx.doi.org/10.1007/s11165-007-9047-8

Enuoka, L.O. (2005). Managing Ethno-Religious Violence and Area Differentiation in Kaduna Metropolis. In A.M. Yakubu et al (eds), Crisis and Conflict Management in Nigeria. Since 1980. Vol. 2. P. 633 Baraka Press and Publishers Ltd., Kaduna, Nigeria.

Federal Republic of Nigeria. (2004). The National Policy on Education. Lagos: government Press.

Francis, H.A. (2013). Using Jigsaw Technique as an Effective Way of Promoting Co-operative Learning Among Primary Six Pupils in Fijai. International Journal of Education and Practice, 1(6), 64-74.

Gay, G. (2004). Beyond Brown: Promoting equality through multicultural education. Journal of Curriculum and 
Supervision, 19(3), 193-216.

Ghosh, R., \& Abidi, A.A. (2004). Education and the Politics of Difference: Canadian Perspective. Toronto: Canadian Scholars' Press.

Kagan, S. (2001). Kagan structures: Research and Rationale. Retrieved from http://www.kaganonline.com/free_articles/dr_spencer_kagan/research_in_nutshell

Keramati, M. (2010). Effect of cooperative learning on academic achievement of physics course. Journal of Computers in Mathematics and Science Teaching, 29(2), 155-173.

Lucas AC. (2000). Jigsaw Lesson for Operatıons of Complex Numbers'. PRIMUS (Problems, Resources, and Issues in Mathematics Undergraduate Studies), 10(3), 219-22.

Machaisa, P. (2004). The Experiences of Learners in Former White Schools. Unpublished M.Ed.-Dissertation. Pretoria: University of Pretoria.

Maduabum .C. (2006). Reforming Government Bureaucracies in Nigeria: The Journey So Far. Lagos, ASCON.

Moreno, R. (2009). Constructing knowledge with an agent-based instructional Program: A comparison of cooperative and individual meaning making. Learning and Instruction, 19(5), 433-444. http://dx.doi.org/10.1016/j.learninstruc.2009.02.018

Moronkola, O.A. (2012). The Development of the School Health Policy and Curriculum in Nigeria. In N. Taylor, M. Littledyke, F.Quinn \&R.K.Coll [Eds], Rotterdam: Sense Publishers. Pages: 107-114

Nevin, E. (2008). Education and sustainable development. Policy \& Practice: A Development Education Review, 6, 49-62.

Ogunleye, B. O. (2002). Evaluation of Environmental Aspect of the Senior Secondary School Chemistry Curriculum in Ibadan, Nigeria. Unpublished Ph.D Thesis, University of Ibadan, Ibadan.

Ojebiyi, O.A., \& Salako, E.T. (2013). Effect of Concept Mapping Instructional Strategy on Junior Secondary School Student's Knowledge of Multiculturalism in the Global 21st Century Social Studies Classroom. Journal of Education and Practice, 4(13), 15-21.

Okam C. C. (2002). Reading in new development in Nigerian education issues and insights. (a collection of curriculum papers). Jos. deka publication

Salako, E. T. (2010). Multicultural Education: An Alternative Strategy for Social Transformation. Adeniran Ogunsanya Coll.Of Educ. Journal of Social Studies Education in Nigeria, 1(1), 28-41.

Uwechue, R. (2004). Reflections on the Nigerian Civil War: Facing the Future. New York: Africana Publishing Corporation. 